\title{
FORCE TRANSMISSION ANALYSIS OF SLIDING BLOCK- TYPE HYDRAULIC SUPPORT UNDER IMPACT LOADS
}

\author{
Zeng, X. T. ${ }^{* * *} ;$ Meng, G. Y.,"\# \& Zheng, K. ${ }^{* * *}$ \\ ${ }^{*}$ School of Mechanical Electronic and Information Engineering, China University of Mining and \\ Technology (Beijing), Beijing 100083, China \\ *** Test Center of China Coal Research Institute, Beijing 100013, China \\ ${ }^{* * *}$ Faculty of Mechanical Engineering, Czech Technical University in Prague, Prague 6 16000, \\ Czech Republic \\ E-Mail: mgy@cumtb.edu.cn (" Corresponding author)
}

\begin{abstract}
In thin coal seams mining, the structure and support performances of traditional hydraulic support are strictly limited by the working environment. The new type sliding block-type hydraulic support is dedicated for thin coal seams mining. In order to comprehensively evaluate the load-bearing performance of this support, this study investigated the force state of key parts under the effect of impact loads. First, the numerical analysis model of the support was built in ADAMS software. Then, under the pressure action of the top plate, six key points on the top surface of the top beam were selected and applied with impact loads. Linear slippage pairs between sliding block and base in the model were set as different friction coefficients. Force changes at different hinge joints under various impact loads were obtained, and the influence of different friction coefficients of the sliding block on force transmission was explored. Results indicate that hinge joints are sensitive to impact loads in different degrees and thus exert dissimilar influences on the friction coefficient of the sliding block. This study is helpful for structural optimization and strength design of sliding block-type support.

(Received in October 2018, accepted in January 2019. This paper was with the authors 1 month for 1 revision.)
\end{abstract}

Key Words: Impact Load, Sliding Block, Hinge Joint Force, Friction Coefficient, Hydraulic Support

\section{INTRODUCTION}

The hydraulic support, which is the main carrying mechanism in the coal mining face, is an important link for safe and high-efficiency underground coal mining process $[1,2]$. The supporting capacity of hydraulic support is influenced by various factors, for instance, load mode and load position [3]. Among these factors, the supporting performance of hydraulic support under impact loads has a significant influence on safe mining process.

The hydraulic support is effective in thick and medium-thick coal seams mining $[4,5]$. However, for thin coal seams mining, the structure, supporting performance of traditional hydraulic support are greatly influenced by narrow and low working environment. To overcome these shortcomings, a new type of sliding block-type hydraulic support, which is dedicated for thin coal seams mining, is designed in recent years [6]. This support replaces the traditional support in which upright column directly supports the top beam with the new structure of "upright rod-sliding block-regulatory oil cylinder." In thin coal seams mining, the dynamic impact load caused by roof crushing and collapse and periodic roof weighing has the strongest influence on stability of the support. Therefore, an investigation on force changes at hinge joints, the hydraulic oil cylinder, and its vibration is detailed studied in order to evaluate the force transmission characteristics and stability of the sliding block-type support.

\section{STATE OF THE ART}

Since the sliding block-type hydraulic support is a new kind of support in thin coal seams mining, only few researches on its performance analysis, especially on force transmission 
analysis are related. Yang et al. built a reverse kinematics model of sliding block-type hydraulic support, and analysed force and motion for each part in this hydraulic support by using Matlab/Simulink software [6]. They proved this new sliding block-type support has less demand on oil pressure for the hydraulic cylinder compared with traditional support, but force transmission analysis under impact loads was not performed to evaluate the load-bearing performance.

Despite few researches on this new hydraulic support, several scholars have carried out intensive researches on traditional hydraulic support. Meng et al. established a mathematical model of load carrying performance of hydraulic support under various loads, and its distribution characteristics were analysed [7]. Zeng et al. put up with a pose adjusting simulation model to monitor and control the pose of hydraulic support [8]. Zeng et al. studied the load transfer characteristics of a two-legged support, and they analysed the impact effects of the hinge joints in hydraulic support under various impact loads [9]. This method provides reference of force transmission analysis for sliding block-type support. Qu et al. established a transverse motion equation of hydraulic pipe and simplified the support as an equivalent and a spring. They investigated the dynamic characteristics under various support stiffness conditions by using bidirectional fluid-solid coupling analysis method [10]. Zhao et al. conducted a finite element analysis of welded joint of the support with stress concentration, implemented fatigue test, and then obtained its fatigue life curves to study and improve fatigue strength of the hydraulic support [11]. Verma and Deb established and analysed a 2D finite element model of the long-arm coal mining wall panel, obtained the interaction between support and surrounding rock, and evaluated the working face by taking hydraulic supports with different bearing capacities as study objects [12]. Wang et al. conducted stress and stability analysis of the double-telescopic prop of the hydraulic support through finite element analysis and obtained safety coefficients of members at different parts of the prop [13]. Sun et al. analysed bearing characteristics of the shield-type hydraulic support, conducted load test in the factory by taking a double-telescopic prop of one model as the study object, provided the correct testing method, and improved the testing efficiency [14]. Oblak et al. introduced an optimal method based on mathematical programming method for determining two groups of parameters of the hydraulic support [15]. Fang et al. studied the welding method in the manufacturing process of hydraulic supports and used automatic twin-wire welding and twinwire gas metal arc welding for Q690 cylinder welding, which could evidently improve welding speed, deposition rate, and welding quality [16]. Zhang et al. studied and evaluated air-tightness of the oil cylinder used for the hydraulic support, obtained the method for improving service life of the sealing ring of the oil cylinder through experimental test, reduced leakage, and lengthened service life of the support [17]. Prebil et al. discussed the comprehensive optimization problem of four-bar mechanism of the support and obtained the optimal region satisfying pre-set conditions using the adaptive mesh refinement algorithm [18]. These studies on supporting efficiency, stiffness, intensity, stability, and reliability of traditional hydraulic support provide significant references for force transmission analysis of sliding block-type hydraulic support.

Based on the above-mentioned studies, a certain type of sliding block-type hydraulic support is taken as an example to analyse the force changes at hinge joints when the top beam is under impact load, force change of the hydraulic oil cylinder and its vibration. Then, force transmission characteristics and stability of the sliding block-type support are evaluated. Finally, analysis results and discussions are conducted and discussed.

The remainder of this study is organized as follows. Section 3 establishes the numerical simulation model of the sliding block-type hydraulic support and determines impact loads, positions, rigidity values of regulatory oil cylinder and balance ram. Section 4 discusses force 
changes at hinge joints, the hydraulic oil cylinder, and its vibration under various impact loads and frictional coefficients. Section 5 summarizes the conclusions.

\section{METHODOLOGY}

\subsection{Modelling of the sliding block-type hydraulic support}

In order to analyse the mechanical response of the sliding block-type hydraulic support under impact load, multibody dynamical simulation platform ADAMS is used for loading simulation. The change in the impact load and its acting position can cause minor deformation of the support structure. This deformation will influence force equilibrium relation and force transmission process of the entire support. Thus, the simulation based on a rigid model cannot satisfy the requirements of problems analysed in this study. ADAMS is advantageous because it is based on kinematics of mechanism and kinetic analysis of the rigid body. However, its function of establishing flexible members is restricted. Thus, the professional flexible pretreatment software HYPERMESH is used to conduct meshing of top beam, shield beam, and front and rear rods of the support, establish rigid connection regions, add material properties (density of $7860 \mathrm{~kg} / \mathrm{m}^{3}$, Young's modulus of $2.1 \times 10^{11} \mathrm{~Pa}$, and Poisson's ratio of 0.3 ) and cell properties, and build load steps. Finally, $m n f$ format files of ADAMS format are generated for establishing a dynamical model of the support. Fig. 1 shows the mesh plot of structural parts of the support generated in HYPERMESH software. The box in the figure represents a rigid connection region established at each hinge joint. A major node exists at the centre of symmetry of each hinge joint and is connected to all sub-nodes in this region. Related constraint pairs are built on major nodes to transmit the force to sub-nodes and then to the entire parts.

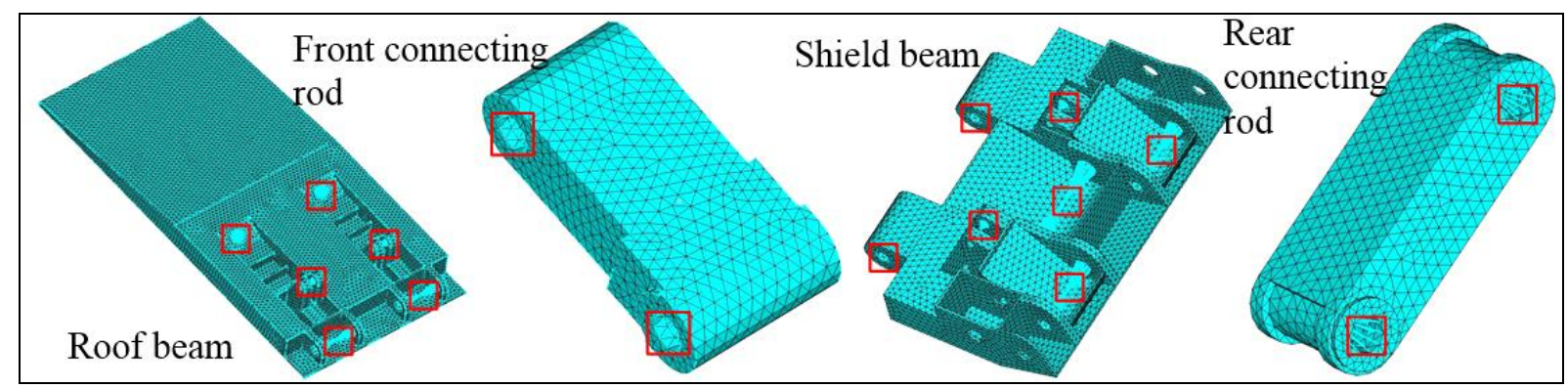

Figure 1: Flexible mesh plot of structural parts of sliding block-type hydraulic support.

The numerical analysis model of the sliding block-type support under impact load is established in ADAMS software, as shown in Fig. 2, where 1 is spring damping system of the balance ram, 2 is shield beam, 3 is front connecting rod, 4 is rear connecting rod, 5 is spring damping system of the regulatory oil cylinder, 6 is sliding block, 7 is base, 8 is upright rod, 9 is top beam, and a-d are respectively hinge joint of shield beam of the top beam, hinge joint of the front rod, hinge joint of the rear rod and hinge joint of the sliding block on the base. The working height of $1.5 \mathrm{~m}$ is set for the support in the model. Related material properties of the entire support model are assigned. An auxiliary mark point is established at the centre of symmetry of hinge joints of each member for the convenience of follow-up constraint addition. Flexible replacement of top beam, shield beam, and front and rear rods is conducted. Related constraints are added between members. Specifically, "rotary pairs" are used for hinge pin connection. "Spherical hinge pairs" are adopted between upright rod and top beam and between upright rod and sliding block. "Deadlock pairs" are added between base and ground, and the base acted as the rack. "Linear slippage pairs" are used between sliding block and slideway on the base, and normal pressure frictional properties are added. The friction 
coefficients are set as $0.1,0.3$, and 0.5 in accordance with the simulation order to analyse the influence of different friction coefficients between sliding block and slideway on force transmission of the sliding block-type hydraulic support. A spring damping system is also established between sliding block and top beam and between shield beam and top beam, and their rigidity values ae set as those previously calculated to complete the replacement of regulatory oil cylinder and balance ram. "Roof pressure" and "impact load" are applied following the aforementioned process. A downward gravitational field perpendicular to the support base is added as well to complete the establishment of the entire simulation system.

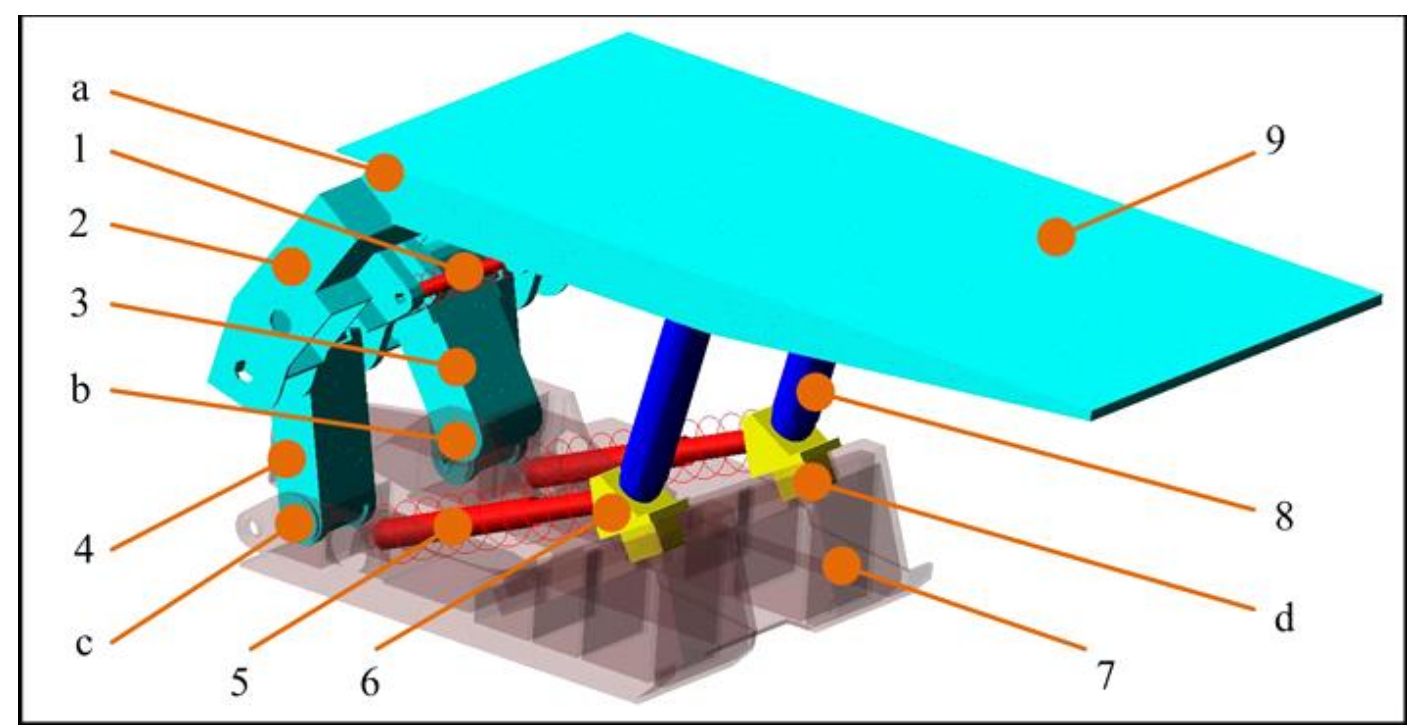

Figure 2: Simulation model of sliding block-type hydraulic support.

\subsection{Determination of impact loads and positions}

The maximum working resistance of the selected sliding block-type support in this study is $3000 \mathrm{kN}$. Thus, $2100 \mathrm{kN}$ is selected as the roof pressure under stable operation of the support in the simulation, which is realized by two active loads $F_{a}$ and $F_{b}$ vertically applied to the top surface of the top beam at one-third of its length direction. After the support adapted to the roof pressure and reached a stable status, the impact load is initiated at the centre of symmetry of the top surface on the top beam. The impact loads of $300 \mathrm{kN}, 600 \mathrm{kN}$, and $900 \mathrm{kN}$ are used for the simulation experiment to analyse sensitivity degrees of hinge joints of the sliding block-type hydraulic support to impact load. Fig. 3 shows the force value curves of active and impact loads; the active load can be realized through the functional step (time, 0, 0, 0.5, 1050000), and the impact load can be realized through functional steps (time, 0.8, 0, 0.81, 300000), (time, 0.8, 0, 0.81, 600000), and (time, 0.8, 0, 0.81, 900000). Fig. 4 presents the concrete load application position. Six points on the centre-line of symmetry of the top surface of the top beam with an equal spacing of $500 \mathrm{~nm}$ are used as acting positions of impact loads $F_{1}-F_{7}\left(F_{1}\right.$ acts on the rear end of the top beam, whereas $F_{7}$ acts on the forefront end of the top beam). During the analysis, $F_{1}-F_{7}$ are activated along the length direction from the rearmost end to forefront end of the top beam. After one-group analysis is completed, step function of the impact load is modified, followed by the analysis of the next group until all groups are explored. 


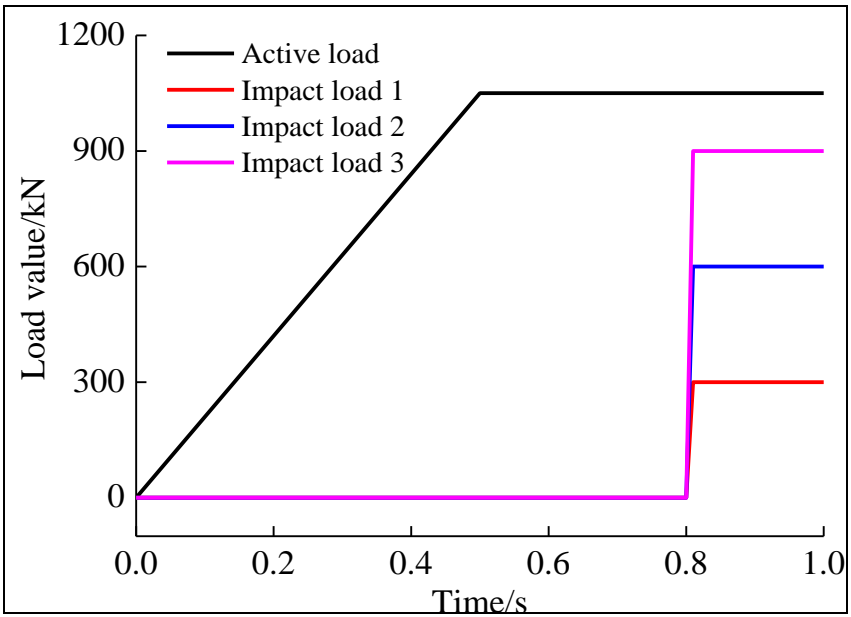

Figure 3: Load curves of active load and impact load.

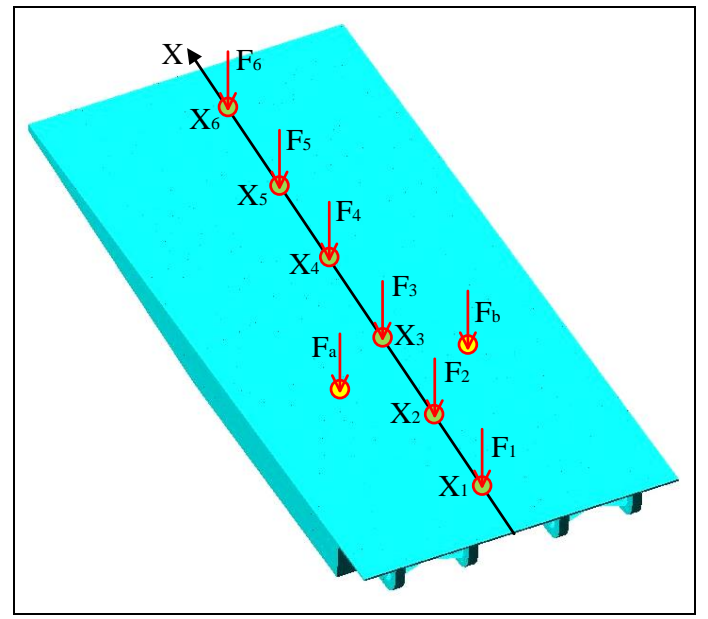

Figure 4: Loading positions of impact loads.

\subsection{Determination of rigidity values of regulatory oil cylinder and balance ram}

The height of the support will be decreased under the effects of normal roof pressure and impact load. Therefore, the use of rigid connecting rod in the simulation model to replace regulatory oil cylinder and balance ram for the analysis could not simulate related height lowering actions of the support. For the sliding block-type support, its sliding block could not slide along the slideway on the base, which would influence the follow-up analysis of frictional force of the sliding block. Accordingly, spring damping system is used to equivalently replace regulatory oil cylinder and balance ram. This way could not only realize motion of the sliding block along the slideway but also could satisfy compression-boosting characteristics of oil fluid in the hydraulic cylinder. The computational formula of equivalent rigidity of the hydraulic cylinder and related parameters of the regulatory oil cylinder and balance ram are shown as follows.

$$
K=\frac{A \beta}{L}
$$

where, $K$ is the equivalent stiffness coefficient $(\mathrm{N} / \mathrm{m}), A$ is effective area when the hydraulic cylinder transfers fluid pressure $\left(\mathrm{m}^{2}\right), \beta$ is the bulk modulus of elasticity of hydraulic fluid and $\beta=1.95 \times 10^{3} \mathrm{~K} / \mathrm{MPa}$ for the oil-in-water emulsion, and $L$ is the length of effective fluid column in the hydraulic cylinder (m).

Table I: Main parameters of regulating cylinder and balance jack.

\begin{tabular}{|c|c|c|c|}
\hline Hydraulic cylinder & $\begin{array}{c}\text { Diameter of } \\
\text { hydraulic cylinder } \\
(\mathrm{mm})\end{array}$ & $\begin{array}{c}\text { Diameter of } \\
\text { hydraulic bar }(\mathrm{mm})\end{array}$ & $\begin{array}{c}\text { Length of effective liquid } \\
\text { column }(\mathrm{mm})\end{array}$ \\
\hline Balance jack & 377 & 320 & 365 \\
\hline \begin{tabular}{l|l} 
& $1^{\text {st }}$ class cylinder
\end{tabular} & 110 & 105 & 290 \\
\hline $\begin{array}{l}\text { Column } \\
2^{\text {nd }} \text { class cylinder }\end{array}$ & 100 & 95 & 207 \\
\hline
\end{tabular}

Eq. (1) and Table I show that the equivalent rigidity values of lower and upper cylinders of the regulatory oil cylinder and that of the balance ram are $K_{1}=6.4 \times 10^{7} \mathrm{~N} / \mathrm{m}, K_{2}=7.4 \times 10^{7}$ $\mathrm{N} / \mathrm{m}$, and $K_{3}=2.06 \times 10^{7} \mathrm{~N} / \mathrm{m}$, respectively. Comprehensive rigidity of the regulatory oil cylinder $K_{4}$ can be calculated using spring-series rigidity, as expressed in Eq. (2).

$$
K_{4}=\left(K_{1} \times K_{2}\right) /\left(K_{1}+K_{2}\right)=3.43 \times 10^{7} \mathrm{~N} / \mathrm{m}
$$




\section{RESULT ANALYSIS AND DISCUSSION}

Force changes of hinge joints and oil cylinder of the sliding block-type hydraulic support are investigated under the effect of different impact loads and in consideration of the influence of roof pressure before the impact load acts. Force increment $\Delta F$ after the impact load acts is used to determine the force change of hinge joints of the support. In the result graph, $x$ coordinate shows the acting positions $X_{1}-X_{7}$ of impact loads of the top surface on the top beam and $y$-coordinate represents the force increment $\Delta F$ or decrement.

\subsection{Force analysis under different impact loads}

Force changes of hinge joints of shield beam of the top beam and front and rear rods under different impact loads are shown in Figs. 5, 6, and 7, respectively.

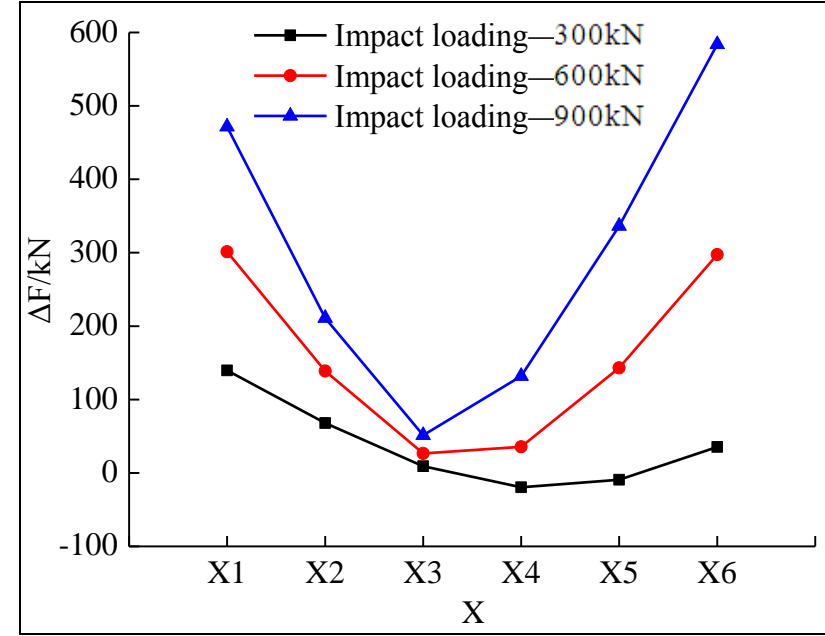

Figure 5: Hinge point force change of top beam and shield beam.

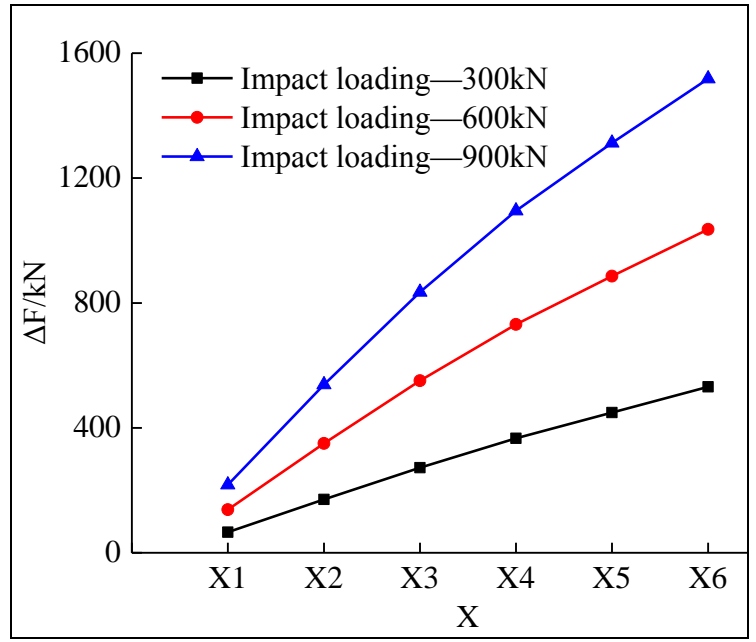

Figure 6: Hinge force change of front connecting rod.

Fig. 5 shows that the response of hinge joint of shield beam of the top beam to impact force is evident. When the impact load is $300 \mathrm{kN}$, force increment $\Delta F$ is negative near $\mathrm{X}_{4}$ and $\mathrm{X}_{5}$, which indicates that force value at this hinge joint is decreased. Force increment $\Delta F$ is positive near $\mathrm{X}_{1}, \mathrm{X}_{2}, \mathrm{X}_{3}$, and $\mathrm{X}_{6}$, whereby the increment near $\mathrm{X}_{1}$ is the maximum and the decrement near $\mathrm{X}_{4}$ is the maximum. Under the impact load of $600 \mathrm{kN}, \Delta F$ values are all positive, which indicates that the force at this hinge joint is increasing. In particular, increments near $X_{1}$ and $X_{6}$ are the maximum, whereas those near $X_{3}$ and $X_{4}$ are the minimum. When the impact load is $900 \mathrm{kN}$, force value at this hinge joint is also increasing. Specifically, the increment at $\mathrm{X}_{6}$ is the maximum, whereas that at $\mathrm{X}_{3}$ is the minimum. At the same impact position, $\Delta F$ generally increases as the impact load increases. When impact load is applied along the length direction of the top beam, force increment $\Delta F$ at this hinge joint first presents a decreasing trend and then shows an increasing trend. For different impact loads, the increments $\Delta F$ are also different. When the impact load is large, the increment or decrement rate is high. When the impact load is small, the increment or decrement rate is low. An analysis of Fig. 6 indicates that force change at the hinge joint of the front connecting rod presents the following characteristics. Under different impact loads, force increments $\Delta F$ at this hinge joint are all positive, which indicates that the force value at this hinge joint is increasing. The minimum increment is located at $\mathrm{X}_{1}$, whereas the maximum increment is located at $\mathrm{X}_{6}$. Along the length direction of the top beam, force increments all present 
progressively increasing tendencies. When the impact load is large, the force increment $\Delta F$ and its increment or decrement rate are high.

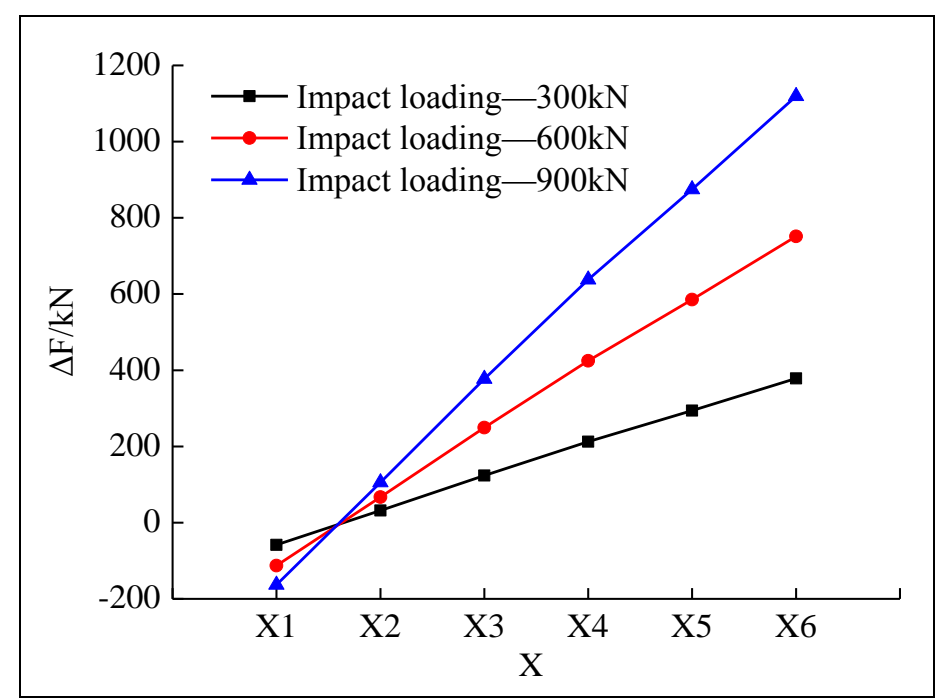

Figure 7: Hinge force change of rear connecting rod.

Fig. 7 shows that the force change at the hinge joint of the rear connecting rod is very similar to that at the hinge joint of the front connecting rod. The difference is that force increment $\Delta F$ from $\mathrm{X}_{1}$ to $\mathrm{X}_{2}$ at the hinge joint is negative, which indicates the force value is decreasing. When the impact load is large, the force value considerably decreases.

Force changes of regulatory oil cylinder, balance ram, and upright rod and frictional force and displacement changes of the sliding block under different impact loads are shown in Figs. 8 to 11 .

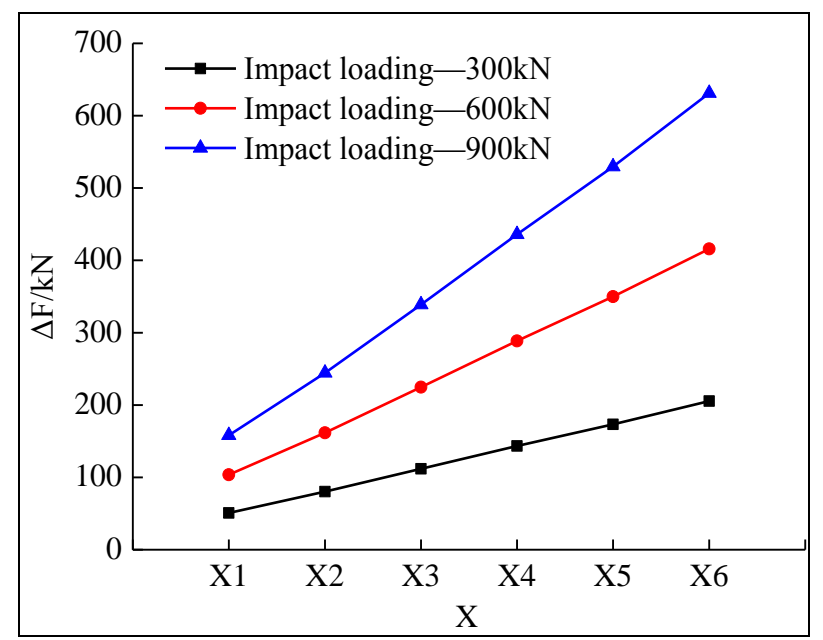

Figure 8: Regulating cylinder force change.

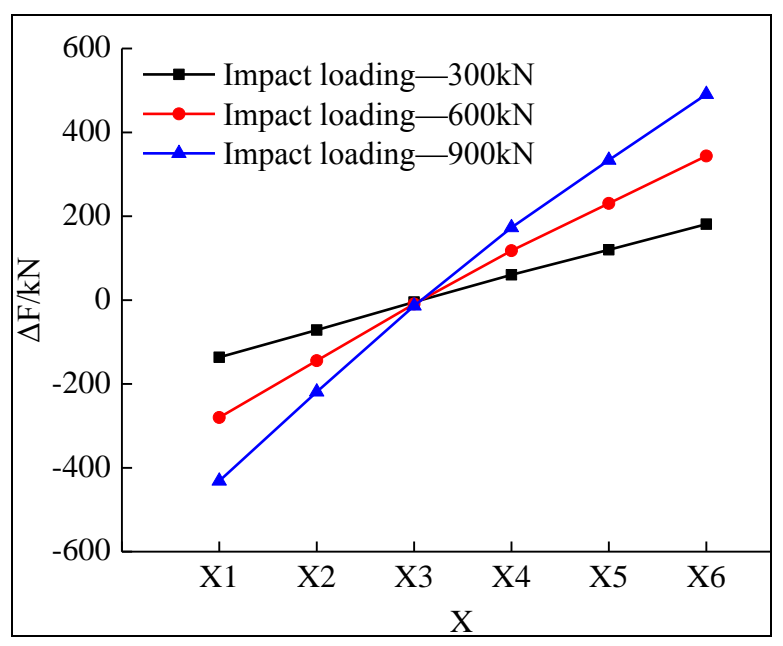

Figure 9: Balance jack force change.

Figs. 8,10 , and 11 show that increments $\Delta F$ of force borne by regulatory oil cylinder, force borne by the upright rod, and frictional force borne by the sliding block have identical response tendencies to impact loads. When the impact load is applied along the length direction of top beam, all $\Delta F$ values present progressive increasing tendencies. The force increment at $X_{1}$ is the minimum, whereas that at $X_{6}$ is the maximum. When the impact load is large, the force increment $\Delta F$ and its increment or decrement rate are high. Fig. 9 reveals that force increment $\Delta F$ within sections $\mathrm{X}_{1}-\mathrm{X}_{3}$ of the balance ram is negative, which indicates that the force is decreased. When the impact load is large, the decrement is high. Notably, the 
decrement at $\mathrm{X}_{1}$ is the maximum. $\Delta F$ within sections $\mathrm{X}_{4}-\mathrm{X}_{6}$ is positive, which indicates that the force increases. When the impact load is large, the increment is high. Notably, the increment at $\mathrm{X}_{6}$ is the maximum.

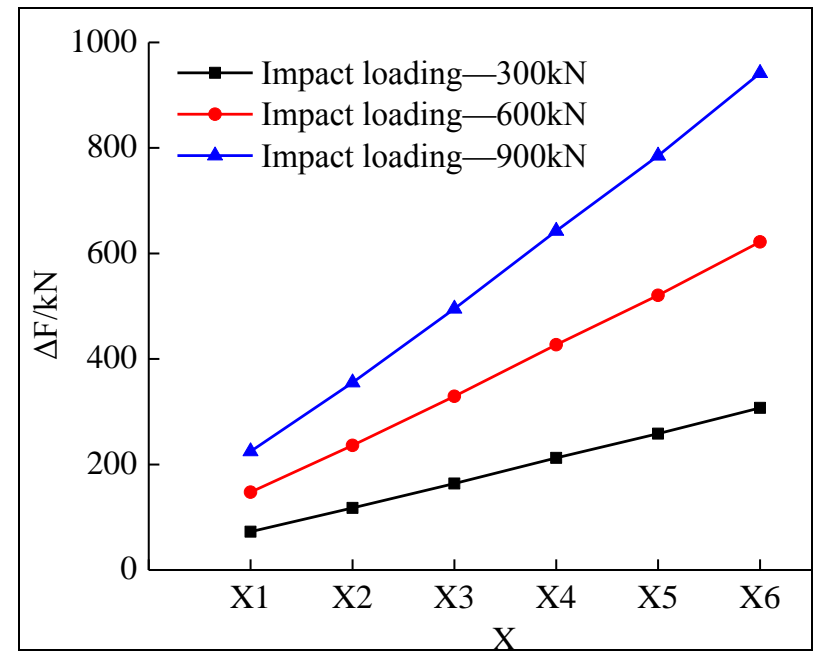

Figure 10: Standing pole force change.

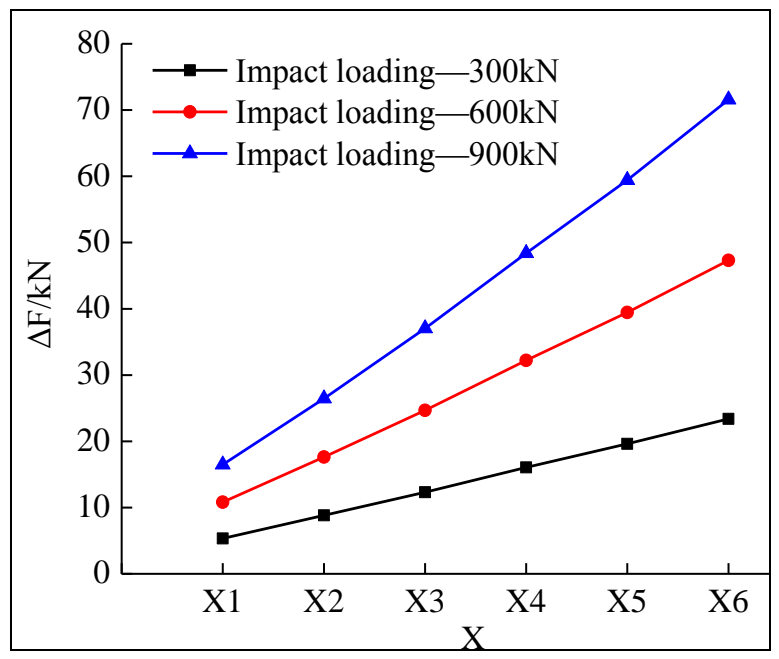

Figure 11: Friction change of sliding block.

\subsection{Force analysis under different frictional coefficients of the sliding block}

The influences of frictional coefficients of the sliding block in the hydraulic support on force conditions at each hinge joint are comprehensively analysed. The relationship between force condition at each part of the support and frictional coefficient of the sliding block under the impact load of $900 \mathrm{kN}$ is obtained by changing frictional coefficient $(0.1,0.3$, and 0.5$)$ of linear slippage pairs between the sliding block and base. The result maps are drawn in unified formats, where $x$-coordinate represents the acting positions $\mathrm{X}_{1}-\mathrm{X}_{7}$ of the impact load on the top surface of the top beam and $y$-coordinate shows the force value $F$.

Changes in force conditions at hinge joints of shield beam of the top beam and front and rear connecting rods with frictional coefficient of the sliding block under the impact load of $900 \mathrm{kN}$ are shown in Figs. 12 to 14 respectively.

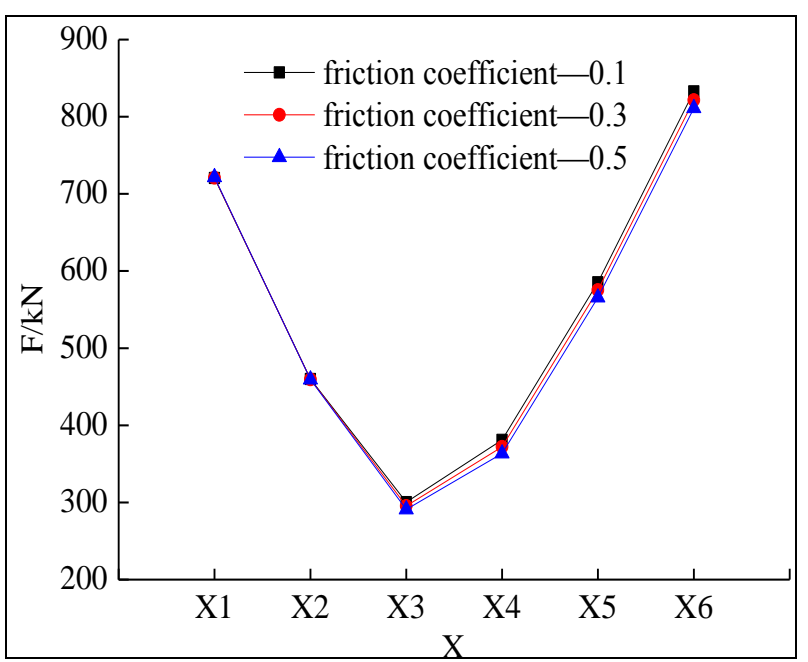

Figure 12: Hinge point force change of top beam and shield beam.

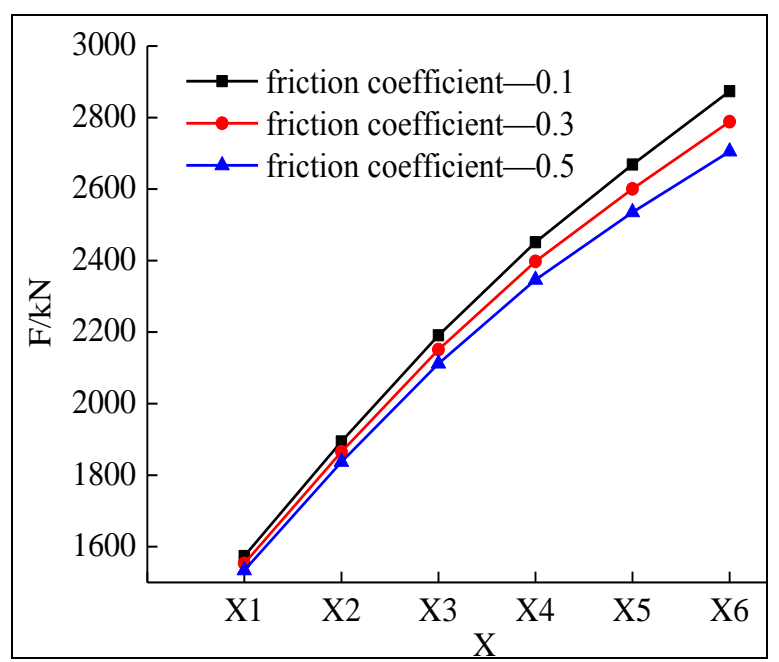

Figure 13: Hinge force change of front connecting rod.

Fig. 12 shows that force condition within sections $X_{1}-X_{3}$ at the hinge joint of shield beam of the top beam bears minor influence from frictional coefficient of the sliding block. Within 
sections $\mathrm{X}_{3}-\mathrm{X}_{6}$, force borne by the hinge joint of shield beam of the top beam is decreased slightly as the frictional coefficient increases. Fig. 13 indicates that, as the frictional coefficient increases, force borne by the hinge joint of the front connecting rod is evidently decreased. The decrement at $\mathrm{X}_{6}$ is the maximum.

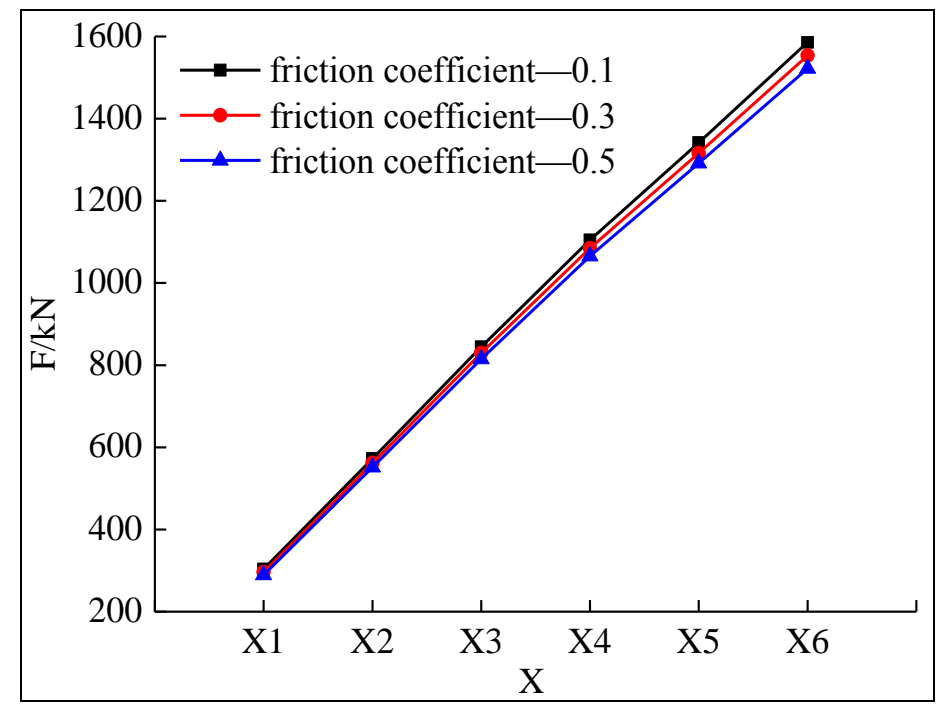

Figure 14: Hinge force change of rear connecting rod.

An analysis of Fig. 14 implies that the influence of frictional coefficient of the sliding block on force condition of the rear connecting rod is very similar to that of the front connecting rod. In particular, when the frictional coefficient of the sliding block is large, the force borne by the rear connecting rod is small. However, the decrement of its force value is smaller than that of the front connecting rod. As frictional coefficient of the sliding block increases, forces borne by shield beam of the top beam and front and rear connects are generally decreased. Moreover, the front connecting rod bears the largest influence from frictional coefficient of the sliding block. When the impact load acts on $\mathrm{X}_{6}$, hinge joints at the three positions bear the largest influence from frictional coefficient of the sliding block.

\subsection{Vibration analysis of the force-bearing oil cylinder}

Impact load, which is an approximately mutating load, will generate a large impact on the support immediately after it acts. Thus, the original force balance state of the support will be broken. After stability for a certain while, the support will reach a new force balance state. The balance process of the support after the impact was explored in this study, which was concretely embodied by vibration conditions of regulatory oil cylinder and balance ram, to comprehensively analyse the influence of impact load on force condition of the support. Figs. 15 and 16 show the vibration conditions of regulatory oil cylinder and balance ram under the impact load of $900 \mathrm{kN}$ and frictional coefficient of 0.1 .

Figs. 15 and 16 show that, when the impact load starts acting at $0.8 \mathrm{~s}$, regulatory oil cylinder and balance ram experience force fluctuation. However, the regulatory oil cylinder reaches force balance state more quickly than the balance ram. When the impact load is applied along the length direction $\left(\mathrm{X}_{1}-\mathrm{X}_{6}\right)$ of the top beam, the time needed to reach force balance state first decreases and then increases. The impact load near the needling of top beam has the minimum influence on force fluctuation of regulatory oil cylinder and balance ram, whereas the impact load at the forefront of the top beam has the largest bearing on force fluctuation of the balance ram. 

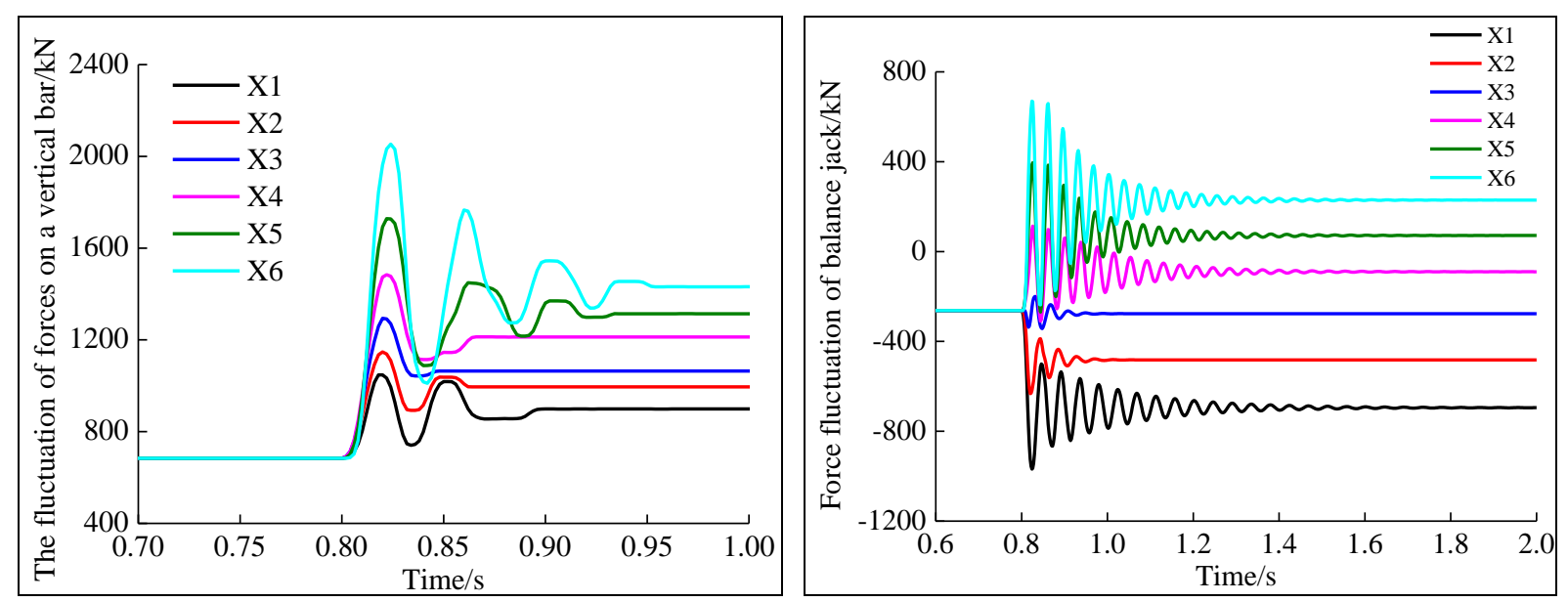

Figure 15: Force fluctuation of regulating cylinder. Figure 16: Force fluctuation of balance jack.

\section{CONCLUSION}

To comprehensively evaluate the carrying capacity of the new sliding block-type hydraulic support, the simulation model of the support was built in ADAMS software, and rigidity values of regulatory oil cylinder and balance ram of the support was determined. Force analysis of the support under various impact loads and frictional coefficients, and vibration analysis of the force-bearing oil cylinder were performed. Force transmission behaviour under impact loads was obtained. Conclusions are drawn as follows.

(1) In terms of acting position of impact force, when the forefront (load position $\mathrm{X}_{6}$ ) of the top beam of the new sliding block-type support is under an impact load, stress conditions at its hinge joints can bear the largest influence. When the middle part of the top beam is under an impact load, the acting position of impact force has the minimum influence on stress conditions of shield beam of the top beam and balance ram. When the rearmost end (load position $\mathrm{X}_{1}$ ) of the top beam is under an impact load, the acting position of impact force has the minimum influence on stress conditions of front and rear connecting rods, regulatory oil cylinder, and upright rod.

(2) As for the impact force, different hinge joints have different response degrees to dissimilar impact loads. Based on the magnitude of the force increment $\Delta F$, hinge joint forces of front and rear connecting rods have the most sensitive response to the impact force, followed by regulatory oil cylinder, balance ram, and upright rod, and the frictional force of the sliding block has the weakest response to the impact force.

(3) Under different frictional coefficients of the sliding block, stress conditions at different parts of the support present dissimilar states. Specifically, regulatory oil cylinder and frictional force of the sliding block bear the largest influence from the frictional coefficient of the sliding block. By contrast, stress conditions of shield beam of the top beam and front and rear connecting rods bear the minimum influence from the frictional coefficient. Notably, stress conditions of upright rod and balance ram are nearly not influenced by the frictional coefficient.

(4) Under the same impact load, vibration of the balance ram is more intense than that of the regulatory oil cylinder. They have different response to acting position of the impact load. In particular, the force fluctuation of the oil cylinder caused by the impact load near the needling is small, whereas that caused by the forefront impact load of the top beam is large (stable at $380 \mathrm{kN}$ ).

This study is helpful for structural optimization and strength design of the sliding blocktype hydraulic support. However, since this new type of hydraulic support is designed for thin coal seams mining face, research on this type support is still relatively insufficient. In future 
research, pose adjusting analysis, and failure analysis for this new type hydraulic support should be considered.

\section{ACKNOWLEDGEMENT}

This work was supported by National Key Research and Development Program of China (Grant No. 2016YFC0600907) and the National Natural Science Fund of China (Grant No. U1361127).

\section{REFERENCES}

[1] Zhang, Q.; Zhang, J.-X.; Qi, W.-Y.; Zhou, N.; Tai, Y. (2017). Structure optimal design research on backfill hydraulic support, Journal of Central South University, Vol. 24, No. 7, 1637-1646, doi:10.1007/s11771-017-3569-7

[2] Zhang, Q.; Zhang, J.-X.; Tai, Y.; Fang, K.; Yin, W. (2015). Horizontal roof gap of backfill hydraulic support, Journal of Central South University, Vol. 22, No. 9, 3544-3555, doi:10.1007/s11771-015-2894-y

[3] Wan, L. R.; Liu, P.; Meng, Z. S.; Yang, Z. K. (2018). Analysis of floor pressure of hydraulic powered support for ultra high mining, Journal of Shandong University of Science and Technology (Natural Science), Vol. 37, No. 5, 34-39

[4] Yuan, Y.; Tu, S. H.; Wang, F. T.; Zhang, X. G.; Li, B. (2015). Hydraulic support instability mechanism and its control in a fully-mechanized steep coal seam working face with large mining height, Journal of the Southern African Institute of Mining and Metallurgy, Vol. 115, No. 5, 441447

[5] Cao, L.-M.; Sun, S.-J.; Zhang, Y.-Z.; Guo, H.; Zhang, Z. (2018). The research on characteristics of hydraulic support advancing control system in coal mining face, Wireless Personal Communications, Vol. 102, No. 4, 2667-2680, doi:10.1007/s11277-018-5294-4

[6] Yang, Y.; Zeng, Q. L.; Zhou, J. H.; Wan, L. R.; Gao, K. D. (2018). The design and analysis of a new slipper-type hydraulic support, PloS ONE, Vol. 13, No. 8, Paper e0202431, 22 pages, doi:10.1371/journal.pone.0202431

[7] Meng, Z. S.; Zeng, Q. L.; Gao, K. D.; Kong, S.; Liu, P.; Wan, L. R. (2018). Failure analysis of super-large mining height powered support, Engineering Failure Analysis, Vol. 92, 378-391, doi:10.1016/j.engfailanal.2018.04.011

[8] Zeng, X. T.; Meng, G. Y.; Zhou, J. H. (2018). Analysis on the pose and dynamic response of hydraulic support under dual impact loads, International Journal of Simulation Modelling, Vol. 17, No. 1, 69-80, doi:10.2507/IJSIMM17(1)412

[9] Zeng, Q.-L.; Meng, Z.-S.; Wan, L.-R.; Wang, C.-L. (2018). Analysis on force transmission characteristics of two-legged shield support under impact loading, Shock and Vibration, Vol. 2018, Paper ID 3854684, 10 pages, doi: $10.1155 / 2018 / 3854684$

[10] Qu, W.; Zhang, H. L.; Li, W.; Sun, W. Q.; Zhao, L. N.; Ning, H. H. (2018). Influence of support stiffness on dynamic characteristics of the hydraulic pipe subjected to basic vibration, Shock and Vibration, Vol. 2018, Paper ID 4035725, 8 pages, doi:10.1155/2018/4035725

[11] Zhao, X. H.; Li, F. Y.; Liu, Y.; Fan, Y. J. (2015). Fatigue behavior of a box-type welded structure of hydraulic support used in coal mine, Materials, Vol. 8, No. 10, 6609-6622, doi: $10.3390 / \mathrm{ma} 8105325$

[12] Verma, A. K.; Deb, D. (2013). Numerical analysis of an interaction between hydraulic-powered support and surrounding rock strata, International Journal of Geomechanics, Vol. 13, No. 2, 181 192, doi:10.1061/(ASCE)GM.1943-5622.0000190

[13] Wang, X. W.; Yang, Z. J.; Feng, J. L.; Liu, H. J. (2013). Stress analysis and stability analysis on doubly-telescopic prop of hydraulic support, Engineering Failure Analysis, Vol. 32, 274-282, doi:10.1016/j.engfailanal.2013.04.006

[14] Sun, H.-B., Jiang, J.-Q., Ma, Q. (2011). Research on hydraulic-powered roof supports test problems, Journal of Coal Science and Engineering (China), Vol. 17, No. 2, 201-206, doi:10.1007/s12404-011-0218-x

[15] Oblak, M.; Harl, B.; Butinar, B. (2000). Optimal design of hydraulic support, Structural and Multidisciplinary Optimization, Vol. 20, No. 1, 76-82, doi:10.1007/s001580050138 
[16] Fang, C.-F.; Meng, X.-H.; Hu, Q.-X.; Wang, F.-J.; Ren, H.; Wang, H.-S.; Guo, Y.; Mao, M. (2012). TANDEM and GMAW twin wire welding of Q690 steel used in hydraulic support, Journal of Iron and Steel Research International, Vol. 19, No. 5, 79-85, doi:10.1016/S1006706X(12)60104-6

[17] Zhang, X.; Liu, J.; Wang, Z.-Y.; Liu, H.-P. (2011). The research of the evaluation system for the sealability of hydraulic supports and jacks' seals, Journal of Coal Science and Engineering (China), Vol. 17, No. 1, 104-106, doi:10.1007/s12404-011-0120-6

[18] Prebil, I.; Krašna, S.; Ciglarič, I. (2002). Synthesis of four-bar mechanism in a hydraulic support using a global optimization algorithm, Structural and Multidisciplinary Optimization, Vol. 24, No. 3, 246-251, doi:10.1007/s00158-002-0234-y 